\title{
Applying Knowledge Management in Generating and Using Evidence in Health Research Priority Setting (HRPS)
}

\author{
${ }^{1}$ Alliance for Improving Health Outcomes \\ ${ }^{2}$ Development Academy of the PhilippinesManila
}

Ma. Rowena H. Alcido, ${ }^{1,2}$ Joseph V. Oraño ${ }^{1}$ and Lester Sam A. Geroy ${ }^{1}$

\begin{abstract}
Background. Current international recommendations in generating and using evidence in Health Research Priority Setting (HRPS) include the use of systematic reviews, and systematic or scientific situational analysis. In the Philippines, the Philippine National Health Research System's (PNHRS) National Guidelines for Health Research Prioritization recommends the use of either a Combined Approach Matrix (CAM) or situational analysis in generating and using evidence for HRPS. At present, there is a lack of a gold standard in generating and utilizing evidence in HRPS.
\end{abstract}

Objective. The primary objective of this paper is to document a practical yet alternative/innovative approach on how evidence was generated and utilized in the process of HRPS as observed in the development of the National Unified Health Research Agenda (NUHRA) in the Philippines. Specifically, it identifies the types of knowledge products produced and their role in the process of health research agenda setting; how evidence was used and managed in the course of NUHRA development; and, the lessons learned from the experience.

Methods. This case study is descriptive of the experience of generating and utilizing evidence for HRPS in the Philippines. The study utilized primary and secondary data. Knowledge Management (KM) was used as a lens to describe the process of generating and managing information for the NUHRA. Document analysis was used in comparing and aligning data with the integrated KM framework.

Results. Pre-selected data were captured and created; shared and disseminated; and subsequently acquired and applied voluntarily by stakeholders during the process of HRPS. Relevant data was presented into various information products designed with a specific stakeholder in mind. Technical papers were developed to cater to national level stakeholders and focused on broad, nationally-relevant issues. Regional situational analysis reports focused on regional and local data and were designed for regional stakeholders to use during the development of Regional Unified Health Research Agenda (RUHRA). Infographics were developed to present the findings of the technical papers creatively and concisely and the NUHRA methodology and were presented to both national and regional stakeholders. The RUHRAs and the NUHRA were the outputs of the health research prioritization activities and will be made available through local and national channels of the PNHRS.

Recommendations. Opportunities for formalization and institutionalization of knowledge management for generating and using evidence in HRPS may be explored to address health information fragmentation across the health research system.

Key Words: evidence-based health research priority setting, knowledge management in health research, health information system, knowledge management

Corresponding author: Lester Sam A. Geroy, MD, MPH, MSc

Alliance for Improving Health Outcomes

62 West Avenue, Quezon City 1104, Philippines

Email: lelim22@yahoo.com 


\section{INTRODUCTION}

Health research priority setting (HRPS) is a crucial activity that can define the health system landscape by focusing attention and allocating resources to health problems and challenges that can be resolved through the conduct of research. Every six years, the Philippine National Health Research System (PNHRS), a network of health research stakeholders, unveils a new research agenda known as the National Unified Health Research Agenda (NUHRA). The NUHRA consolidates the efforts of the different public agencies particularly the Department of Health, the Department of Science and Technology and other government agencies, private and nongovernment organizations and serves as one of the unifying activities of the PNHRS. ${ }^{1}$ The outcome of any research priority setting exercise is founded on the quality and availability of relevant data in informing rational decisions. ${ }^{1}$ However, even before a national guideline for HRPS was formalized, the PNHRS produced two NUHRAs in the past. The information used to develop the first NUHRA in 2006, which covered the years 2006 to 2010, was primarily anchored on the National Objectives for Health in 2005. ${ }^{1}$ The subsequent NUHRA, which was released in 2011 and covered the years 2011 to 2016, utilized information from stakeholders within the four core agencies of the PNHRS, namely Department of Health (DOH), Department of Science and Technology (DOST), Commission on Higher Education (CHED) and the University of the Philippines Manila-National Institutes for Health (UPM-NIH). ${ }^{2}$ Its framework was based on the six health system building blocks of World Health Organization (WHO). Moreover, the two earlier versions of the NUHRA were developed under the influence of international and national policy instruments namely: the Millennium Development Goals, the Philippine Development Plan, midterm development plans of $\mathrm{DOH}$ and DOST, and other relevant policies and plans within the same period.

International recommendations on generating and using evidence in HRPS include the use of systematic reviews ${ }^{3}$; and systematic or scientific situational analysis of the country's health status, health care system and health research systems, user-felt needs (wants) and user demands (expressed needs) and values. ${ }^{4}$ In 2016, the PNHRS released the National Guidelines for Health Research Prioritization, a seminal work recommending a three-phase approach to the creation of a health research agenda. The PNHRS guidelines recommends the use of either a Combined Approach Matrix (CAM) or situational analysis in generating and using evidence for HRPS. At present, there is no gold standard on a practical approach to generating and utilizing evidence in HRPS.

For NUHRA 2017-2022, the lack of a singular recommendation in approaching the use of evidence in HRPS became a design dilemma during its planning stages.

\section{Knowledge Management}

Knowledge Management (KM) as defined by Davenport in 1994 is "the process of capturing, distributing and effectively using knowledge". ${ }^{5} \mathrm{KM}$ originated from and successfully grew in the business world and has been applied at the organizational level for decades and "increasingly within global health and development, to spark innovative thinking, improve strategic decision making and encourage dynamic learning". ${ }^{6}$ Health-related institutions and organizations can use KM to share pertinent health knowledge at all levels of the health system, promote a culture of collaboration and learning, and tackle human resource-related issues in preserving organizational knowledge to enhance "decisionmaking, processes and services". ${ }^{6}$ The integrated knowledge management cycle is a framework that combined various models of knowledge management. Developed by Dalkir in 2005, the model has three stages: knowledge capture and/or creation; knowledge sharing and dissemination; and, knowledge acquisition and application. ${ }^{7}$ Integral to the cohesion of these stages as a cycle are assessment after knowledge capture and/or creation; contextualization after knowledge sharing and dissemination; and, update after knowledge acquisition and application and before restarting the cycle at knowledge capture and/or creation.

Knowledge management has practical applications and has been recently used by Johns Hopkins Center for Communication Programs to create a roadmap for implementing global health programs. The concept of knowledge management and its applications to health, particularly health research, is further explored in this paper.

\section{OBJECTIVES}

This paper is part of the efforts in documenting the Philippine experience on HRPS in the context of developing NUHRA 2017-2022, especially in light of the novel approach to and recognition of the agenda as a Philippine public policy. The general objective of the paper is to describe how evidence was generated and utilized in the process of HRPS.

Specifically, this paper aims to: (1) describe the type of information produced and their role in the process of health research agenda setting, (2) identify what KM elements were applied in generating the evidence for NUHRA development, and (3) recommend how evidence can be further embedded in the process of HRPS through the application of KM approach within the PNHRS.

\section{METHODS}

This case-study is descriptive of the process of generating evidence through a process that involved knowledge management elements in the process of HRPS for NUHRA 2017 to 2022. The project of developing the NUHRA was commissioned by the Philippine Council for Health Research and Development of the Department of 
Science and Technology (DOST-PCHRD) and had the goal of producing the NUHRA and a Regional Unified Health Research Agenda (RUHRA) for each of the 17 regions in the country. The authors were part of the research team that steered the process of developing the NUHRA and oversaw the technical requirements of the project throughout the project life cycle. The project ran from January to October 2017.

Primary data sources included field notes, and presentations produced by the implementing team during the course of NUHRA development. Secondary data sources included published and grey literature accessed online.

Data were processed and analyzed using the integrated knowledge management cycle as a lens to distil from the NUHRA experience elements of the knowledge management framework. Steps in the generation and use of evidence in the process of HPSR were compared with the standard definitions of the knowledge management elements and organized as such. Data analysis was done post- project implementation.

\section{RESULTS}

\section{Information products for NUHRA 2017-2022 Development}

Information products, namely: technical papers, regional situational reports, and infographics, containing both scientific and contextual evidence, were produced by the research team to guide NUHRA development. They were developed with the peculiar needs of national and regional stakeholders in mind.

A review of the steps on how evidence was generated and utilized during the conduct of HRPS for the NUHRA, revealed that evidence or knowledge was selected, gathered, packaged, presented, utilized, questioned, modified, and stored. Applying the integrated knowledge management cycle as a lens to these processes, the entire process may be described according to three KM elements: knowledge capture and/or creation, knowledge sharing and dissemination, and knowledge acquisition and application.

\section{DISCUSSION}

Four (4) technical papers were developed to cater to the information needs of national level research stakeholders and to encourage organized thinking and analysis of the health research environment using a policy and system perspective. These papers focused on broad, nationallyrelevant issues including (1) current Philippine socioeconomic development and health directions, (2) future health sector trends and challenges, (3) health research milieu in the country, and (4) private sector participation in health research.

Regional situational reports were prepared to inform regional research stakeholders of the health situation in the region during the development of Regional Unified Health Research Agenda (RUHRA). These were provided in recognition of the variability of health needs and health research environments across the regions. A situational analysis report presenting mainly regional and local data were developed for each of the 17 regions of the country highlighting research priorities unique to the region yet still aligned with the rest of the national health research directions. These reports adhered to an outline geared towards the Essential National Health Research (ENHR) strategy established and advocated by the COHRED. ${ }^{2}$ The contents of these reports also aided in the analysis of the regional health research system and in the assessment of health research management in the regions.

Infographics, which are visual diagrams summarizing information and data, were also developed to present the findings of the four technical papers creatively and concisely and to present the methods the research team employed in generating the NUHRA and the RUHRAs. The infographics were presented to both national and regional stakeholders.

The outputs from convening research stakeholders to form the NUHRA and the 17 RUHRAs yielded to the final informational products of the process of HRPS at the national and regional levels, respectively. These can be considered as informational products in themselves.

\section{Elements of Integrated Knowledge Management Cycle in Generating and Using Evidence for Health Research Priority Setting}

\section{Knowledge Capture and/or Creation}

The purpose behind generating evidence for priority setting was to frame the national and regional context and to generate, as objectively as possible, timely and relevant national and local data. This was achieved through several steps. Firstly, a thorough literature review was completed: mostly from academic papers in writing the technical papers, information on previous Philippine experience on HRPS, and PNHRS Guidelines for Agenda Setting. This was further enhanced by key conducting key informant interviews were conducted to produce the technical papers and situational reports. Overall, the evidences generated for the HRPS activities were information products developed consistent under sound research principles and methodologies. These information products were also packaged into brief reports with a written abstract and formatted for publication.

\section{Knowledge sharing and dissemination}

Findings from the technical papers and regional situational reports were presented during national and regional consultations for the NUHRA. In these one- to two-day events, the informational products were presented to research stakeholders through a verbal discussion and a full-text hardcopy of the technical papers and the regional situational reports were also included. Research stakeholders 
were encouraged to give feedback and vet the evidence presented during the consultations. As for the final outputs of the consultation, the NUHRA and RUHRAs were to be released through channels within the PNHRS.

\section{Knowledge acquisition and application}

During the conduct of the regional and national consultations, research stakeholders utilized the information products by critiquing and validating evidence, providing additional information to existing information, and citing the information in the report as basis for the inclusion of a research topic in the agenda.

\section{Lessons Learned and Possible Implications in using Knowledge Management Approaches in HRPS}

Generating quality and timely information to guide HRPS is challenging given the inherent fragmentation of information in the Philippine health system. A Knowledge Management approach to organizing information flows within the national health research system has the potential to address fragmentation by dedicating technology, processes and people in building a repository of relevant information; ensuring information is accessible at all levels of the system; and, developing an evidence-based approach to all types of research including the process of HRPS. In the current HRPS experience for the NUHRA, the study by Ramos-Jimenez and Arguelles in $2010^{8}$ was the evidence which helped set the goals for NUHRA 2017-2022. However, this important document was almost missed during the literature review because it was unpublished and inaccessible. A systematic organization of knowledge and accessibility of both published and unpublished evidence to support decision-making within the health research system could never be overemphasized.

In this vein, the next NUHRA, as well as future HRPS exercises, should be undertaken with the recognition of the paramount role of knowledge management. Information gathering, synthesis and packaging must be prioritized and performed with a generous lead time prior to the implementation of an HRPS exercise. The entire body of knowledge products that were created during and after the conduct of HRPS should also be published for future planning and strategy mapping.
Another important concept in Knowledge Management is the cyclical nature of knowledge generation. The knowledge products produced in the HRPS may be considered as living documents that, at one point from hereon and until 2022, may be revised to adapt to the changing research milieu and influx of new information. A mid-term assessment for instance may reveal new problems or new solutions that may be added to the current health research agenda.

\section{Statement of Authorship}

All authors approved the final version submitted.

\section{Author Disclosure}

All authors declared no conflict of interest.

\section{Funding Source}

This paper was funded by the Philippine Council for Health Research and Development.

\section{REFERENCES}

1. Philippine National Health Research System. National Unified Health Research Agenda 2006-2010. Taguig City: PNHRS; 2006. pp. 1-6

2. Philippine National Health Research System. National Unified Health Research Agenda 2011-2016. Taguig City: PNHRS; 2011. p. 1.

3. Nasser M, Crowe S. An introduction to Research Priority Setting (RPS) for research groups in the Cochrane Collaboration [Internet]. Plymouth (UK); n.d. [cited 2018 April 9]. Available from: http:// methods.cochrane.org/sites/methods.cochrane.org.prioritysetting/ files/public/uploads/

4. Okello D, Chongtrakul P, The COHRED Working Group on Priority Setting. A manual for research priority setting using the ENHR strategy [Internet]. Lausanne, Switzerland; 2000 March [cited 2018 March 27]. Available from: http://www.cohred.org/downloads/578.pdf

5. Koenig M. What is KM? Knowledge Management Explained [Internet]. Camden, ME: KMWorld; 2018 Jan 15 [cited 2018 April 9]. Available from: http://www.kmworld.com/Articles/Editorial/WhatIs/What-is-KM-Knowledge-Management-Explained-122649.aspx

6. Salem RM, Harlan SV, Mazursky SF, Sullivan TM. Building Better Programs: A Step-by-Step Guide to Using Knowledge Management in Global Health. Baltimore, MD: The Knowledge for Health Project, Johns Hopkins Center for Communication Programs; 2017. pp. x-xi

7. Dalkir K. Knowledge Management in Theory and Practice. Boston, MA: Elsevier; 2005. pp. 43-45

8. Ramos-Jimenez P, Aragones DCG, Mendoza YF, Togonon LD, Yubia MC, Amita GA. Assessment of the 2011-2016 National Unified Health Research Agenda (NUHRA) and the 2011-2015 Regional Unified Health Research Agenda (RUHRA). 2016. p.109 Unpublished. 